\title{
Triassic extinction or Jurassic vacuum?
}

\section{from Andrew Milner}

IN Charles Kingsley's The Water Babies, the author makes the observation that one cannot claim that water babies do not exist until one has seen them not existing. This little paradox is particularly pertinent to the fossils of terrestrial animals and what we deduce about them, particularly when they are absent from rocks of a given age.

If a taxon is absent from the fossil record for a given period of time, we logically assume that either it was genuinely absent or that it was present but that circumstances did not permit preservation. If the taxon or its descendants subsequently reappear as later fossils or living forms, we can be certain that the absence was due to non-preservation. If it never reappears the problem remains open and becomes: when did this taxon become extinct? Attributing a point in time to an extinction is only valid when the fossil record is comparably complete before and after the supposed event. Only if an animal is absent from an otherwise rich assemblage or if its ecological replacement is present, can one claim to have seen that animal "not existing".

The discovery of a temnospondyl amphibian in the Lower Jurassic of Australia announced by Warren in this week's issue of Nature (page 435) is a reminder of this. The Order Temnospondyli radiated during the Carboniferous to reach its greatest diversity in the Upper Carboniferous and Lower Permian. Many lineages became extinct during the Permian but others extended into and through the Triassic, and by the late Triassic several families remained, including the capitosaurs, brachyopids, metoposaurs and plagiosaurs. That the extinction of these families had taken place at the end of the Upper Triasic was virtually dogma. So much so that, as Warren notes, an earlier discovery of a fragment of Jurassic temnospondyl had been assumed to be a reworked bone from the Triassic simply because there was no precedent for it to have been any younger.

However, in order to have such fossils of Lower or Middle Jurassic amphibians or terrestrial vertebrates, one must first have vertebrate-bearing continental sediments of the same age and these are singularly scarce. The Upper Triassic of Europe. North America. Africa. India and China has produced an extensive range of terrestrial vertebrates including temnospondyl amphibians, procolophonids, chelonians, thecodonts, rhynchosaurs, dicynodonts,

and early dinosaurs, crocodiles and mammals. By the Upper Jurassic, a very different assemblage of continental vertebrates is known from Europe, North America and East Africa. The chelonians, crocodiles, dinosaurs, pterosaurs and mammals predominate. The temnospondyls, procolophonids, rhynchosaurs, thecodonts and dicynodonts are all absent, presumed extinct, and in most cases their ecological replacements can be seen to be present. But when were they replaced? Did they become extinct synchronously on the Triassic-Jurassic boundary as a literal interpretation of the record would suggest? Or were they gradually replaced during the Lower and Middle Jurassic? Warren's amphibian suggests the latter possibility as do the tritylodonts which extend from Upper Triassic to Middle Jurassic.

\section{Astrophysics in Boston}

\section{from James Pringle}

The Eighth Texas Symposium on Relativistic Astrophysics took place on December 13-17, 1976 in the Copley Plaza Hotel in Boston, Massachusetts. The proceedings of the Symposium will be published as a special issue of the Annals of the New York Academy of Sciences. Nearly a thousand astronomers and physicists were present for this biennial jamboree and there might have been many more but for the competing attraction of the midJanuary American Astronomical Society which was taking place in Hawaii.

$\mathrm{X}-\mathrm{RAY}$ astronomy featured prominently in four of the ten sessions. In the session on X-ray astronomy itself $\mathbf{R}$. Novick (Columbia University) reported on the first unambiguous detection of polarised radiation in X-ray astronomy. With the $X$-ray polarimeter on board OSO 8 , he and his group have found that at X-ray energies the Crab Nebula is $22 \%$ polarised with a significance of some 15 standard deviations. This compares with $19 \%$ polarisation in the optical. The position angle of the polarisation is essentially the same in both energy bands. He presented marginal evidence for the polarisation of the $X$ rays from the Crab pulsar itself. and indications that the swing in position angle of the X-ray polarisation
Several recent discoveries offer the hope that this problem will eventually be solved. A sauropod dinosaur has recently been described from the Lower Jurassic Kota formation of India (Jain et al., Proc. R. Soc. B188, 211; 1975) and new microvertebrate localities of Middle Jurassic age have been found on the Isle of Skye (Waldman and Savage, J. geol. Soc. 128, 119; 1972) and in Oxfordshire (Freeman, Science 194, 1053; 1976). We still do not have a rich assemblage of early Jurassic terrestrial vertebrates but further excavation of these localities and Warren's Queensland locality may provide us with enough material to characterise the Lower and Middle Jurassic faunas and hence determine the chronology of the turnover of terrestrial vertebrate taxa between the Upper Triassic and Upper Jurassic. direction through each pulse is comparable to that seen in the optical. In addition Cygnus X-1 may be polarised at the $3 \%$ level (a $2 \frac{1}{2}$ standard deviation result) and, at a higher level of confidence, Cygnus X-2 may be polarised at the $5 \%$ level. E. Boldt (Goddard Space Flight Center) reported on some further high time resolution observations of the black hole candidate X-ray source Cygnus X-1, which continues to display $\mathrm{X}$-ray activity on timescales as short as a few milliseconds. He gave tentative evidence that there may be a repetitive occurrence in these millisecond bursts with a timescale of about $10 \mathrm{~ms}$ and speculated that this might be identified with material falling within the last stable circular orbit for a black hole of some 17 solar masses.

Ken Pounds (University of Leicester) gave a preliminary report on the catalogue of $\mathrm{X}$-ray sources being prepared from data from the Ariel V satellite and on a programme of optical identification of previously unidentified high galactic latitude sources (UHGLs for short). He argued that most of the 50 or so UHGLs in the UHURU catalogue of X-ray sources arc now accounted for and so the UHGL mystery is solved, although the attentive in the audience noted that he had at the onset reported some 45 new UHGLs found by Ariel V.

The discovery of bursting behaviour 